\title{
Equoterapia na percepção de pais/mães de autistas
}

\author{
Riding therapy on the perception of parents/mothers of autistic \\ Terapia de conducción en la percepción de padres/madres de autista
}

Recebido: 16/08/2021 | Revisado: 22/08/2021 | Aceito: 24/08/2021 | Publicado: 25/08/2021

\author{
Paulo Cezar Mello \\ ORCID: https://orcid.org/0000-0003-1749-1187 \\ Universidade de Passo Fundo, Brasil \\ E-mail: pcmello@upf.br \\ Helenice de Moura Scortegagna \\ ORCID: https://orcid.org/0000-0001-8604-9005 \\ Universidade de Passo Fundo, Brasil \\ E-mail: helenice@upf.br \\ Cristina Fioreze \\ ORCID: https://orcid.org/0000-0002-7685-6636 \\ Universidade de Passo Fundo, Brasil \\ E-mail: cristinaf@upf.br \\ Graciela de Brum Palmeiras \\ ORCID: https://orcid.org/0000-0001-7963-2358 \\ Universidade de Passo Fundo, Brasil \\ E-mail: graciela@upf.br \\ Cleiton Chiamonti Bona \\ ORCID: https://orcid.org/0000-0003-3269-3879 \\ Universidade de Passo Fundo, Brasil \\ E-mail: cbona@upf.br
}

\begin{abstract}
Resumo
Este estudo teve como objetivo conhecer a percepção dos pais/mães de indivíduos com Transtorno do Espectro Autista acerca da participação na terapia assistida por cavalos. Estudo de abordagem qualitativa, do tipo exploratório-descritivo com delineamento transversal, realizado com dezesseis pais/mães de indivíduos com Transtorno do Espectro Autista participantes do Projeto de Extensão em Equoterapia, vinculado a uma Universidade Comunitária localizada ao norte do Estado do Rio Grande do Sul. Os dados foram coletados no período de novembro e dezembro de 2020, por meio de entrevistas individuais utilizando-se de um questionário semiestruturado. As falas dos pais/mães foram sistematizadas pelo NVivo ®10, que gerou categorias de similaridades e correlações, utilizou-se a análise temática de conteúdo de Bardin. Os pais/mães evidenciaram a percepção de benefícios relacionados a convivência e no desenvolvimento, alterações motoras e interação social, assim como as dificuldades geradas pela pandemia da Covid-19.
\end{abstract}

Palavras-chave: Transtorno do espectro autista; Terapia assistida por cavalos; Interação social; Envelhecer; Gerontologia.

\begin{abstract}
This study aimed to understand the perception of fathers/mothers of individuals with Autistic Spectrum Disorder regarding participation in horse-assisted therapy. A qualitative exploratory-descriptive study with a cross-sectional design, conducted with sixteen parents of individuals with Autistic Spectrum Disorder participating in the Extension Project in Riding Therapy, linked to a Community University located in the north of the State of Rio Grande do Sul. Data were collected from November to December 2020, through individuais interviews using a semi-structured questionnaire. The parents' speeches were systematized by NVivo ®10, which generated categories of similarities and correlations, using Bardin's thematic content analysis. The fathers/mothers showed the perception of benefits related to coexistence and development, motor changes and social interaction, as well as the difficulties generated by the Covid19 pandemic.
\end{abstract}

Keywords: Autistic spectrum disorder; Horse assisted therapy; Social interaction; Age; Gerontology.

\section{Resumen}

Este estudio tuvo como objetivo comprender la percepción de los padres/madres de personas con trastorno del espectro autista con respecto a la participación en la terapia asistida por caballos. Estudio cualitativo exploratorio-descriptivo con un diseño transversal, realizado con dieciséis padres/madres de individuos con Trastorno del Espectro Autista participantes del Proyecto de Extensión de Hipoterapia, vinculado a una Universidad Comunitaria ubicada en el norte del Estado de Rio Grande do Sul. Los datos se recogieron de noviembre a diciembre de 2020, a través de entrevistas individuales mediante un cuestionario semiestructurado. Los discursos de los padres/madres fueron sistematizados por NVivo®10, que generó categorías de similitudes y correlaciones, utilizando el análisis de contenido temático de Bardin. 
Los padres/madres mostraron la percepción de beneficios relacionados con la convivencia y el desarrollo, los cambios motores y la interacción social, así como las dificultades generadas por la pandemia Covid-19.

Palabras clave: Trastorno del espectro autista; Terapia asistida por caballos; Interacción social; Envejecer; Gerontología.

\section{Introdução}

A interação social, quando positiva, para indivíduos com Transtorno do Espectro Autista (TEA) é um dos fatores que contribuem para a qualidade do viver-envelhecer, pois se mostra importante para saúde psicológica e fundamental para evitar o isolamento.

A melhora na convivência faz parte de um processo longo, que depende de diversos fatores interdependentes e relativos ao comprometimento psíquico e a sensibilidade à abordagem terapêutica. Nesse sentido, o cuidado com os indivíduos autistas requer uma intervenção multidisciplinar e o envolvimento dos pais no tratamento terapêutico, decisivo para sua evolução e desenvolvimento (Simões, et al., 2010).

Estimular a convivência com indivíduos, por meio de atividades coletivas, como a equoterapia, dentro de uma rotina, traz benefícios para um envelhecimento saudável da mente e do corpo. Sendo que para Lima, Silva \& Galhardoni (2008), o envelhecimento é um processo heterogêneo e multifacetado, que ocorre ao longo de toda a vida e, apesar de heterogêneo, o envelhecimento é comum a todos os seres e acontece de forma progressiva, implicando em modificações morfológicas, bioquímicas e funcionais. E, quando relacionado aos indivíduos autistas, essas mudanças podem dificultar a qualidade de vida e adaptação ao contexto social (Silva, 2017).

Assim, ressalta-se a importância de se ter terapias que colaborem no dia a dia do autista, pois a família que convive com familiar nesta condição, muitas vezes não sabe como agir em relação aos cuidados necessários para o desenvolvimento pessoal e intelectual e surgem várias dúvidas, podendo ocorrer mudanças no estilo de vida familiar, pois é um transtorno de neurodesenvolvimento que necessita de cuidados por toda a vida (Maia Filho, et al., 2016).

Visando promover melhor qualidade de vida e potencializar a convivência de indivíduos com TEA, destaca-se a equoterapia enquanto possibilidade de intervenção (Barbosa \& Munster, 2019). A intervenção equoterapêutica é capaz de melhorar a autoestima e a autonomia, diminuir a agressividade, aumentar a tolerância, assim como minimizar a frustação, associada a um significativo desenvolvimento da sociabilidade (Barbosa \& Munster, 2019).

Diante deste contexto, o objetivo deste artigo foi verificar a percepção dos pais/mães quanto a participação dos filhos autistas acerca da participação na terapia assistida por cavalos. É importante destacar que este estudo foi realizado no período da pandemia da Covid-19, e o distanciamento social provocou importantes quebras nas rotinas dos indivíduos com autismo e suas famílias. Para essa população em específico, pode ser difícil compreender o cenário pandêmico e todas as ramificações decorrentes da Covid-19, principalmente quando se trata das crianças pequenas e/ou aquelas que apresentam deficiências intelectuais e sensoriais concomitantes ao quadro (Fernandes, et al., 2021).

\section{Método}

Trata-se de um estudo qualitativo, exploratório-descritivo, com delineamento transversal, realizado com os pais/mães de indivíduos com TEA que participam de um Projeto de Extensão em Equoterapia da Faculdade de Educação Física e Fisioterapia (FEFF) de uma Universidade Comunitária ao norte do Estado do Rio Grande do Sul. A pesquisa exploratória permite familiarizar ou construir novas percepções sobre um acontecimento (Zanella, 2011), e a pesquisa do tipo descritiva torna possível descrever episódios relacionado ao objeto em estudo, podendo ser um evento ou fenômeno, ambas se adequaram a esse estudo (Favero \& Gaboardi, 2014; Vergara, 2005). 
Já a abordagem qualitativa, segundo Minayo (2016), trabalha com um universo de significados, motivos, aspirações, crenças, valores e atitudes, o que corresponde a um espaço mais profundo das relações dos processos e dos fenômenos que não podem ser reduzidos a operacionalização de variáveis.

Para fins de compor a população do estudo, foram convidados a participar todos os pais/mães dos autistas matriculados no Projeto de Equoterapia sem exclusão. Assim, a amostra da pesquisa foi composta por dezesseis pais/mães de indivíduos com diagnóstico de TEA que participam regularmente das atividades semanais do Projeto de Extensão em Equoterapia, vinculada a IES. Para identificação nas respostas e posterior análise, os pais/mães respondentes foram identificados como Participante, pela letra P, seguido do numeral, pela ordem de entrevista.

A pesquisa foi realizada nas dependências da Fazenda da Brigada Militar, onde ocorrem as atividades do Projeto de Extensão em Equoterapia. A coleta dos dados, ocorreu por meio de entrevistas individuais, nas dependências da Fazenda da Brigada Militar, durante a realização das sessões de equoterapia, após as autorizações da Coordenação de Extensão e Direção da Unidade e do Coordenador responsável pelo Projeto.

O instrumento para a coleta de dados foi um questionário semiestruturado elaborado a partir do objetivo da pesquisa e fundamentação teórica, composto por perguntas que permitiram ao informante responder livremente, usando a sua linguagem, abrangendo várias facetas do mesmo tema. Os dados coletados foram analisados segundo análise temática de conteúdo (Bardin, 2016), sistematizados e codificados por meio do software NVivo ${ }^{\circledR} 10$.

Bardin (2016) divide a análise de conteúdo em três momentos: a pré-análise; a exploração do material e o tratamento dos resultados, a inferência e a interpretação. Inicialmente realizou-se a pré-análise, a partir de leitura flutuante do que emergiu das entrevistas. Na sequência, foi realizada a abstração do que é relevante e de interesse para o estudo em forma de temas, seguindo os critérios de: exaustividade, representatividade, homogeneidade e pertinência. Depois, na fase de exploração do material, fez-se a síntese da codificação dos recortes de textos em unidades temáticas.

As falas dos participantes foram avaliadas e codificadas por quatro especialistas que realizam pesquisas de abordagem qualitativa (duas enfermeiras, uma assistente social e um profissional de educação física), e sistematizadas e codificadas por meio do software NVivo ${ }^{\circledR} 10$, que gerou categorias de similaridades e correlações.

As análises realizadas por meio do software NVivo ${ }^{\circledR} 10$ envolveram três etapas do processo, apoiadas pela ferramenta: a preparação dos dados, a codificação e análise, e a elaboração do relatório para apresentação dos resultados. Na descrição de cada uma destas etapas são apresentados fragmentos dos dados analisados na pesquisa. As categorias são chamadas de nodes, que representam uma categoria ou uma ideia abstrata e podem armazenar sua definição (Próprio Autor, 2021). Uma vez finalizado o processo de codificação foi possível gerar três categorias (nodes): benefícios da convivência, benefícios do desenvolvimento e as dificuldades frente a pandemia da Covid-19.

Os nodes são apresentados por meio de "nuvens de palavras" de maior frequência das falas dos participantes. A definição foi armazenada em uma caixa gerada automaticamente pelo software no momento da criação da categoria. As similaridades das categorias foram analisadas por meio do coeficiente de correlação linear de Pearson.

Esta pesquisa foi aprovada pelo Comitê de Ética e Pesquisa (CEP) da Universidade Comunitária localizada ao norte do Estado, sob o parecer: 4.107.476 e, de acordo com a resolução 466/12 do Conselho Nacional de Saúde (CNS), todos os participantes assinaram o Termo de Consentimento Livre e Esclarecido (TCLE).

\section{Resultados}

\subsection{Caracterização dos Pais/Mães e Indivíduos com TEA}

Na caracterização dos responsáveis, em relação ao grau de parentesco, dos dezesseis participantes, doze eram mães e quatro eram pais. Embora haja a presença da figura masculina junto às atividades dos participantes do projeto, destaca-se a 
presença prevalente da figura da mãe. E, nesse sentido, Silva, et al. (2020) afirma que após confirmação diagnóstica, as mães são geralmente as mais atingidas, por serem mais presentes no lar, e as principais responsáveis pelo cuidado a este indivíduo.

Quanto à idade das participantes mães, pode-se constatar que variou entre 28 e 78 anos. Além disso, evidenciou-se que duas estavam na faixa etária dos 30 anos, três na faixa de idade dos 40 anos, uma na faixa de idade dos 50 anos e quatro na faixa etária dos 60 anos. Já a idade dos participantes pais estava entre 38 e 67 anos. Um na faixa de idade dos 30 anos, um na faixa de idade dos 40 anos e dois na faixa etária dos 60 anos. Segundo o estudo de Maia Filho, et al. (2018) nas últimas décadas, observouse um aumento na média de idade dos genitores na gravidez e que a magnitude da associação com o TEA foi maior quando ambos os genitores apresentavam idades avançadas.

No que diz respeito ao estado civil, nove dos responsáveis entrevistados eram casados, representado a maioria, divorciados eram três, dois solteiros, e dois em união estável. A escolaridade declarada pela maioria dos responsáveis foi o ensino médio completo, seguida do ensino superior. Foi possível identificar que três pais possuíam especialização e três tinham de um a oito anos de estudo. A maioria dos pais trabalhava mais de trinta horas semanais remuneradas. Seguida daqueles que não exerciam nenhuma atividade laboral.

Na caracterização dos indivíduos com TEA, a idade foi variada, sendo duas crianças, uma com seis anos e outra com oito anos, os demais adolescentes e adultos tinham idade entre quatorze, vinte, trinta e nove e quarenta e três anos. Dos doze alunos que fazem parte do projeto equoterapia, onze são do sexo masculino e apenas uma do sexo feminino.

Em relação ao tempo do diagnóstico de TEA, observou-se que alguns identificaram precocemente, com um ano e onze meses e um tardiamente, com nove anos. A maioria foi diagnosticada entre dois e sete anos. Werner \& Dawson (2005) identificaram que diferenças no desenvolvimento de crianças com TEA, em relação a crianças típicas, ficaram acentuadas após os 13 meses de idade, idade em que as crianças autistas apresentam de maneira mais evidente algumas características como: pouco contato ocular, falta de orientação ao ser chamado pelo nome, falta de engajamento em interações sociais e em habilidade de atenção conjunta.

Quando indagados sobre o tempo de participação no Projeto de Equoterapia da IES, foi relatado que sete dos indivíduos com TEA estão há mais de dez anos e os demais tem de um há três anos de participação no projeto. Sobre como tomaram conhecimento do Projeto, a maioria citou escola de autistas e amigos. Somente duas menções foram feitas da Associação de Pais e Amigos da Criança Autista (AUMA), e apenas um mencionou o profissional médico.

Entre as análises realizadas por meio do software NVivo ${ }^{\circledR} 10$, estão as categorias que são chamadas nodes e apresentadas por meio de "nuvens de palavras" de maior frequência das falas dos participantes, foram selecionadas todas as palavras com extensão mínima de 4 caracteres, excluindo as demais. A Figura 1 apresenta a nuvem de palavras de maior frequência das falas dos participantes que fizeram parte do estudo. 
Figura 1 - Nuvem de palavras de maior frequência das falas dos participantes.

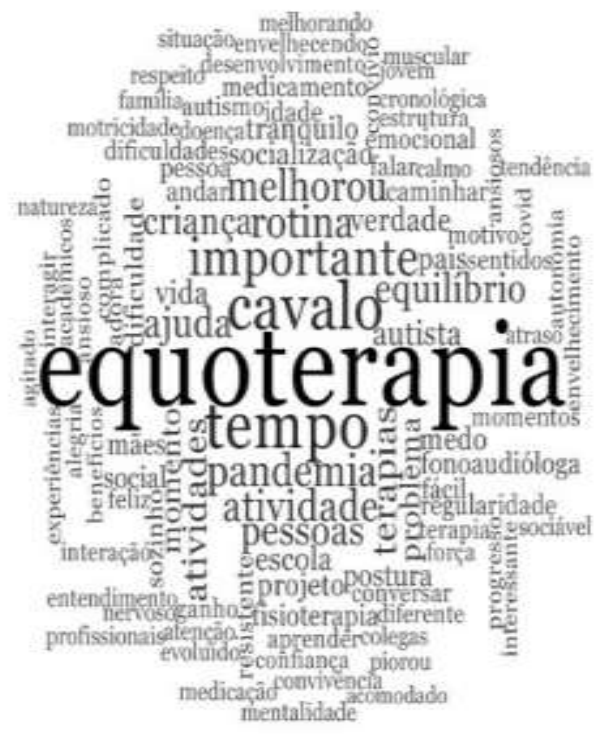

Fonte: Autores (2021).

As dez palavras mais citadas nas falas e suas respectivas referências $\left(\mathrm{n}^{\circ}\right)$ e coberturas $(\%)$ foram: equoterapia $\left(\mathrm{n}^{\circ} 300\right.$ e $2,84 \%)$, tempo ( $\mathrm{n}^{\mathrm{o}} 148$ e $\left.1,40 \%\right)$, cavalo ( $\mathrm{n}^{\circ} 140$ e $\left.1,32 \%\right)$, importante $\left(\mathrm{n}^{\mathrm{o}} 108\right.$ e $\left.0,98 \%\right)$, pandemia $\left(\mathrm{n}^{\mathrm{o}} 76\right.$ e $\left.0,72 \%\right)$, rotina $\left(\mathrm{n}^{\mathrm{o}}\right.$ 76 e $0,72 \%)$, atividade ( $n^{\circ} 75$ e $\left.0,71 \%\right)$, melhorou ( $n^{\circ} 72$ e $0,68 \%$ ), ajuda ( ${ }^{\circ} 68$ e $0,64 \%$ ), pessoas (nº 68 e $\left.0,64 \%\right)$. O número de referência apresenta a quantidade de vezes em que a palavra é citada nas falas dos participantes, e a cobertura refere-se a porcentagem em que a palavra é citada nas categorias.

A partir da análise das informações obtidas emergiram três categorias: benefícios na convivência, benefícios no desenvolvimento e dificuldades no contexto da pandemia, representadas no dendograma de cluster da similaridade de palavras das categorias definidas para a análise do conteúdo. A métrica de similaridade utilizada foi o coeficiente de correlação linear de Pearson (Figura 2).

Figura 2 - Dendograma de cluster da similaridade de palavras das categorias.

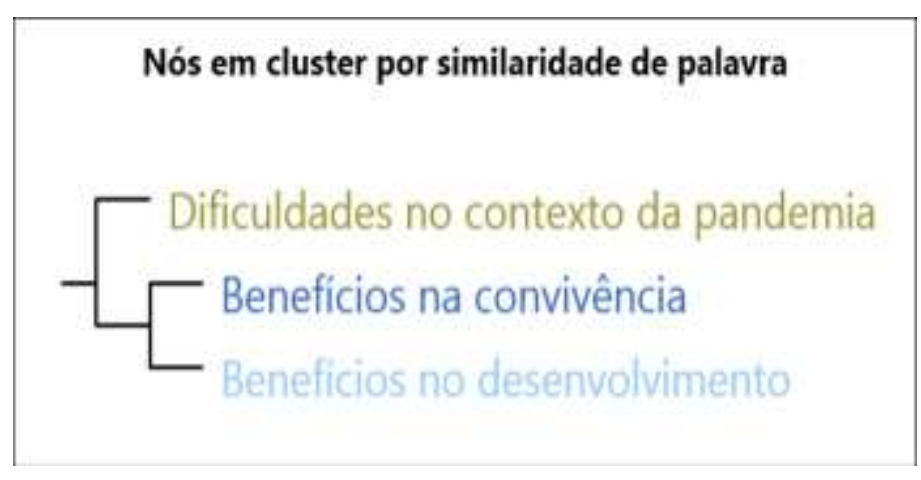

Fonte: Autores (2021).

As comparações realizadas entre as categorias definidas para a análise das falas apresentaram coeficientes de correlação linear de Pearson igual a 0,9, ou seja, todas indicaram alta correlação positiva (Tabela 1). 
Tabela 1. Coeficientes de correlação de Pearson entre as categorias definidas para categorização das falas, Passo Fundo, 2021.

\begin{tabular}{|c|c|c|}
\hline Nó A & Nó B & $\begin{array}{l}\text { Coeficiente de correlação de } \\
\text { Pearson }\end{array}$ \\
\hline $\begin{array}{l}\text { Nós\\
Benefícios no } \\
\text { desenvolvimento }\end{array}$ & Nós\\
Benefícios na convivência & 0,900 \\
\hline $\begin{array}{l}\text { Nós \Dificuldades no contexto da } \\
\text { pandemia }\end{array}$ & $\begin{array}{l}\text { Nós\\
Benefícios no } \\
\text { desenvolvimento }\end{array}$ & 0,891 \\
\hline $\begin{array}{l}\text { Nós \Dificuldades no contexto da } \\
\text { pandemia }\end{array}$ & Nós\\
Benefícios na convivência & 0,888 \\
\hline
\end{tabular}

Fonte: Autores (2021).

\subsection{Benefícios na Convivência}

Os pais/mães dos autistas participantes do Projeto Equoterapia expressaram que a convivência oportunizada por meio da participação de seus filhos nas atividades propostas tem sido significativa no que se refere aos sintomas do TEA. Nesse sentido, para os participantes que os filhos estão há mais de dez anos na equoterapia, a percepção sobre a convivência dos filhos, foi avaliada positivamente como expressa as falas a seguir:

\section{$[\ldots]$ entendemos que faz muito bem para ele, em vários aspectos $(P-01)$.}

[...] com a função dele aprender a conviver com pessoas diferentes, porque, cada vez que ele vem para a terapia é um profissional diferente, que vai conversar com ele, que vai levar ele no cavalo (P-15).

Tuchman e Rapin (2009) afirmam que intervenções precoces, treinamento de habilidades sociais e o treinamento de pais para conviver com os filhos, auxiliam na promoção de benefícios em longo prazo. Essa afirmação ratifica o que a Participante 01 menciona sobre a participação do seu filho no Projeto Equoterapia. Corroborando com a fala anterior, a Participante 02 menciona:

[...] a socialização dele com as outras pessoas também, ele gosta das estagiárias, das meninas, de conversar. Então, pelo incentivo, pelo estímulo que fazem nas oficinas, nas ilhas, ele gosta, está participando bem (P-02).

De acordo com o que foi declarado pelos participantes deste estudo, identificou-se que as transformações próprias da vida adulta e pertinentes ao processo de envelhecimento podem influenciar na adaptação de seus filhos autistas ao contexto social. Nesse sentido, as falas revelam que o fato de a equoterapia ampliar oportunidades de convivência semanalmente de seus filhos trouxe benefício na habilidade de interação e, consequentemente, na habilidade cognitiva, conforme excertos abaixo:

[...] ele tendo essa interação com outras pessoas aumentou também o entendimento dele, ele aumentou o leque de palavras que ele começou a entender $[. .].(P-06)$.

[...] além de tudo também melhorou a socialização, porque lá ele está juntamente com outras crianças, têm outros pais, professores, acadêmicos, público em geral e isso é uma maneira de socializar (P-12).

Apesar de ser compreendido como heterogêneo, o envelhecimento é comum a todos os seres e acontece de forma progressiva, implicando em modificações morfológicas, bioquímicas e funcionais (SILVA, 2017). Essas mudanças podem dificultar a qualidade de vida e adaptação ao contexto social, além de poder tornar os seres mais vulneráveis a doenças (Souza; Skubs \& Brêtas, 2007; Silva, 2017).

Para Farley, et al. (2009) as avaliações dos indivíduos adultos com TEA indicam que pode haver uma redução gradual dos sintomas gerais do autismo nesta fase da vida, em que os principais domínios de dificuldade estão relacionados com a comunicação social, comportamentos e interesses repetitivos, rígidos e estereotipados. 
Um ponto importante a ser destacado é aquele em que os familiares apontam que as dificuldades vivenciadas no período da infância e da adolescência estão diretamente relacionadas às limitações do próprio indivíduo com TEA, como, por exemplo, suas dificuldades de comportamento com o passar do tempo. Nesse sentido, a convivência com os colaboradores e acadêmicos voluntários no projeto foi identificada pelos pais/mães como favorável ao convívio em família, conforme menciona a Participante 15:

[...] Ele tinha muitas crises. Hoje eu percebo que ele está se acalmando na verdade, ele já me escuta, no início ele não te escutava $(P-15)$.

Cabe salientar a importância do trabalho interdisciplinar nos processos de envelhecimento de indivíduos com TEA. Nesse sentido o projeto terapêutico com cavalos, foi apontado pelos participantes do estudo como promissor na contribuição positiva com o desenvolvimento de habilidades sociais e cognitivas de indivíduos com TEA.

É importante destacar que a partir das falas dos participantes algumas perspectivas educacionais para a vida adulta ficaram evidenciadas, principalmente no que tange a busca por locais para convivência, realização de terapias multidisciplinar, acolhimento às famílias, atendimento individualizado e a presença de profissionais qualificados.

\subsection{Benefícios no Desenvolvimento}

Sabe-se que as diferentes manifestações do TEA apresentam constantes desafios para o desenvolvimento evolutivo do indivíduo autista e, também, para a família. Para a maioria dos pais/mães dos autistas que participaram deste estudo, os benefícios no desenvolvimento estão associados a aspectos como melhora na afetividade, na linguagem, na autonomia, na tranquilidade, na disciplina e na independência motora. Para estes a equoterapia tem auxiliado significativamente, como se observa nas falas a seguir:

[...] ele mudou bastante, desde que começou no projeto, vimos notando bastante diferença em todas as partes, tanto na independência, quanto na disciplina (P-01).

[...] ele mudou bastante, desde que começou no projeto. Há bastante diferença em todas as esferas, como na disciplina para executar atividades diárias, na afetividade... na afetividade do relacionamento (P-02).

Para Bastos, et al. (2012) destaca que a dependência de cuidados diários, frequentes em grande parte dos casos, traduzem a necessidade de cuidado do longo da vida, e qualquer mudança que possa gerar uma autonomia é significativa para o indivíduo com TEA.

Newton (2011) afirma que a prática da equoterapia é capaz de desenvolver melhoria na sensibilidade física e psíquica, pois exige uma constante percepção frente a diversas reações e estímulos, resultando em harmonia, equilíbrio físico e psicológico.

Para além disso, com relação ao desenvolvimento a seguir os relatos evidenciam que:

[...] com a equoterapia notei que ele começou a caminhar melhor, o equilíbrio, a postura melhorou bastante (P-03).

[...] melhora em todos os sentidos, é social, postura, equilíbrio, ele não faz muito isso daí, então quando ele vem, quando começa a fazer equoterapia percebemos que ele fica melhor (P-06).

[...] mas com o passar do tempo foi dando para perceber sim essas várias melhoras (P-09).

É importante destacar que o bem-estar proporcionado pelo ambiente familiar gera benefícios ao filho, sendo este o primeiro e o mais importante contexto da aprendizagem e do desenvolvimento, tendo influência nas ações do indivíduo com TEA. É possível observar que na percepção dos pais/mães, a equoterapia tem auxiliado nesse bem-estar, trazendo melhoras 
significativas para o dia-a-dia dos seus filhos. As atividades da equoterapia visam melhorar a qualidade de vida dos pacientes, estimulando o desenvolvimento de habilidades em diversas áreas como, motricidade, cognição, socialização, conduta, linguagem, respeitando a singularidade de cada participante (Guerrero \& Alvarez, 2011).

Os desafios inerentes ao desenvolvimento evolutivo do indivíduo com TEA estão dentro do rol de condições bastante estressantes, como os problemas de comunicação, expressão emocional, que podem causar muita tensão no ambiente familiar (Gomes, 2015). Entretanto evidencia-se nas falas dos Participantes 10 e 03, mudanças no comportamento que está dentro das percepções positivas da equoterapia:

[...] era bem difícil de lidar com ele, depois que ele começou a participar da equoterapia deu pra perceber o desenvolvimento enorme, principalmente na parte afetiva, social, e motor também (P-10).

[...] depois que ele sai da atividade da equoterapia ele fica mais calmo, dorme melhor, é um projeto que trouxe uma ajuda imensa para eles em todos os niveis ( $P$-03).

A maioria dos estudos em equoterapia cita como objetivo da reabilitação a funcionalidade motora e geralmente visa mensurar a aquisição de benefícios físicos como equilíbrio e força em indivíduos com paralisia cerebral (Giagazoglou, et al., 2012; Shurtleff, et al., 2009). O que se percebe pelos relatos dos pais/mães é que houve uma melhora no aspecto motor (equilíbrio, postura), na afetividade, estimulação da linguagem, autonomia, autoestima, tranquilidade e independência.

\subsection{Dificuldades no Contexto da Pandemia}

A China no final do ano de 2019 identificou um vírus com alto potencial de transmissão e contágio, o qual pertence à família do coronavírus conhecida pelos pesquisadores desde a década de 1960. Este por sua vez pode causar graves infecções respiratórias e foi chamado de Covid-19. Com o grande índice de contaminação a Organização Mundial de Saúde (OMS) declarou no começo do mês de março de 2020 que o surto de Covid-19 evoluiu para uma pandemia (Carvalho, et al., 2020). Levanto isso em conta as atividades do Projeto de Extensão Equoterapia foram suspensas, e assim iniciou um novo processo de execução das atividades extensionistas.

Após a suspensão das atividades de campo do Projeto Extensionista de Equoterapia, aguardou-se um tempo e logo em seguida após reuniões remotas com os acadêmicos estagiários retomou-se as atividades com vídeo orientando com cartazes explicando para os indivíduos participantes da equoterapia a respeito dos cuidados em relação a pandemia do coronavírus. Houve a necessidade de auxiliá-los na compreensão deste novo cenário. Após isso, outro vídeo foi feito, este por meio de fotos com todos os indivíduos com TEA participantes do projeto, relembrando alguns momentos marcantes das sessões de equoterapia na Fazenda da Brigada Militar.

Já nos meses seguintes, o Projeto Equoterapia seguiu com reuniões sistemáticas com a equipe de estagiários, iniciando a realização de lives pelo Google Meet, estas foram realizadas mensalmente, sempre no turno da noite para que os indivíduos autistas pudessem participar juntos com seus pais/mães. Para a realização destas lives foram convidados profissionais das áreas da saúde da educação física, fonoaudiologia e psicologia, a ideia era seguir dando suporte emocional e social a estas famílias. No entendimento dos pais/mães dos autistas participantes da equoterapia a parada das atividades durante a pandemia causou dificuldades, como relatado a seguir:

[...] a pandemia foi um horror, eles são muito metódicos muito programáticos, tal dia é isso, segunda é a Equoterapia, terça escola. Aquele mundinho deles caiu por terra, não tem mais Equoterapia, não tem mais as meninas, porque ele gosta muito das estagiárias, ele adora $(P-11)$. 
[...] foi bem difícil começarmos, eles ficando fechados em casa, começaram a ter crises, ele nunca teve crises de quebrar coisas em casa, e ele teve uma crise forte, então tivemos que procurar um médico, aumentar mais o medicamento porque sentíamos que ele não estava bem e precisava de alguma coisa, começamos a fazer caminhadas na rua (P-15).

No início de novembro de 2020 foi possível voltar com as sessões de campo de equoterapia, com a autorização do SESMT (Serviço Especializado em Engenharia de Segurança e Medicina do Trabalho), utilizando-se de inúmeros EPIs (Equipamentos de Proteção Individual), para a efetivação do trabalho de campo, sendo chamado para as sessões de equoterapia um grupo reduzido de beneficiados e estes de forma escalonada. O retorno foi visto de maneira positiva pelos pais/mães, conforme pode ser evidenciado nas falas a seguir:

[...] Nós pais ficamos ansiosos para que voltasse logo, por vários motivos, principalmente por causa dele, faz muito bem esse contato com a natureza, com o cavalo e essa socialização (P-07).

[...] quando ele para de fazer alguma atividade ele tem a tendência a regredir um pouco, ele sentiu muita falta, estávamos na expectativa que voltasse logo por causa que isso ajudaria ele a voltar a ter uma disciplina (P-05).

Salienta-se que no contexto pandêmico houve muitas mudanças significativas na rotina dos indivíduos autistas do Projeto de Extensão Equoterapia, e nesse sentido, as dificuldades no contato com os outros, e as limitações de comunicação destacaram-se. Isso evidencia a importância do trabalho da equoterapia na intervenção dos seus laços sociais, isso especificamente no caso do indivíduo com TEA e de sua família (Brasil, 2015).

Para os pais/mães, o período em que foram suspensas as atividades da equoterapia representou um retrocesso em muitos dos aspectos que estavam percebendo melhora, isto pode ser evidenciado na fala da Participante 12:

[...] vi muito a diferença quando parou, ele estava praticamente meio travado, praticamente forcei mais para ele retornar $(P-12)$.

Quanto a regularidade da participação os pais/mães expressaram que a interrupção das atividades repercutiu no aumento da ansiedade, esquecimento, crises de fúria, perda do equilíbrio, entre outros sintomas. Assim destacam-se as falas dos Participantes 04 e 06 quando indagados sobre a regularidade das atividades do projeto:

[...] parou o projeto da Equoterapia, assim como parou as demais terapias, com esta parada senti que ele ficou mais ansioso, ele ficou mais nervoso (P-04).

[...]. É muito importante a regularidade, porque o autista ele aprende por repetição. Então se tiver uma parada muito grande, eles podem esquecer certas coisas, ou não conseguir gravar (P-06).

Em tempos de pandemia, os desafios e as dificuldades dos pais/mães de autistas aumentaram significativamente ficando evidenciado que a parada temporária nas atividades para os indivíduos participantes do Projeto em Equoterapia foi marcada pela ruptura em suas atividades rotineiras, e que refletiram diretamente em seu comportamento, inclusive refletindo em algumas perdas como esquecimento, autonomia, piora em quadros de crises de agressividade e nervosismo.

\section{Considerações Finais}

Os resultados apresentados evidenciaram a percepção dos pais/mães quanto aos benefícios em relação a participação dos filhos autistas no Projeto Equoterapia, sendo possível inferir que as relações estabelecidas nas sessões entre praticante-cavalo desenvolvem a qualidade e afeição, passando ganhos de autoestima e segurança em seguida existem melhoras no senso de limite 
e responsabilidade. Apresenta-se também avanço na socialização e relacionamento, tendo melhorias nos quadros de ansiedade, independência, e, ainda, crises nervosas.

Apesar do esforço empírico, o estudo apresenta limitações. Assim, reitera-se que o foco foi a percepção dos pais/mães em relação a participação dos seus filhos na equoterapia. A ampliação do escopo do estudo para outras percepções, como por exemplo, por meio de outros profissionais da área da saúde pode contribuir com os resultados.

Sendo assim, evidencia-se a importância desta temática na intervenção no quadro de autismo para o processo de desenvolvimento, interação social, convívio humanizado e vínculo afetivo, principalmente para atender as suas necessidades, proporcionar satisfação e melhoria na qualidade de vida no processo viver-envelhecer dos indivíduos com TEA.

Desta forma, esse artigo não visa esgotar o assunto, mas almeja servir para futuras pesquisas e possibilitar um maior conhecimento e aplicação sobre este tipo de terapia, possibilitando o avanço das pesquisas acerca da temática, com o intuito de compreender e mensurar de que maneira a equoterapia interfere no desempenho de aspectos físicos, cognitivos e sociais do beneficiário.

Sugere-se novos estudos em relação a outros atendimentos alternativos por meio de terapias e intervenções específicas de indivíduos com TEA. De tal modo, que essas intervenções seguirão dando suporte às famílias e, principalmente, aos pais/mães destes indivíduos, os quais se mobilizam assumindo papéis ativos frente a estas limitações e que por diversas vezes buscam terapias para reparar esses prejuízos acarretados pelo TEA. Nesse sentido, considera-se válido o esforço dos pais/mães multiplicarem na busca de atividades dirigidas e específicas, cabendo à sociedade dar suporte por meio de novos estudos e práticas para acolher as particularidades e necessidades dessa população.

\section{Referências}

Barbosa, G. \& Munster, M. A. (2019). Aprendizagem de posturas em equoterapia por crianças com transtorno do espectro autista (TEA). Revista Educação Especial, 32, 38-1-20.

Bardin, L. (2016). Análise de conteúdo. Edições 70.

Bastos, M. B. (2012). Incidências do educar no tratar: desafios para a clínica psicanalítica da psicose infantil e do autismo. 2012. Tese (Doutorado) - Instituto de Psicologia, Universidade de São Paulo.

Brasil. Ministério da Saúde. (2015). Construções e comentários sobre os documentos: Linha de Cuidado para a Atenção das Pessoas com Espectro Autista e suas Famílias na Rede de Atenção Psicossocial do Sistema Único de Saúde/SUS e Diretrizes de Atenção à Reabilitação de pessoas com Transtorno do Espectro do Autista (TEA).

Carvalho, C. L. (2020). Os desafios do envelhecimento e do autismo. <institutomongeralaegon.org>.

Farley, M. A., et al. (2009). Twenty-year outcome for individuals with autism and average or near-average cognitive abilities. Autism Research, Hoboken, 2, (2), 109-118. http://dx.doi.org/10.1002/aur.69.

Favero, A. A., Gaboardi, A. \& Cenci, A. (Coord) (2014). Apresentação de trabalhos científicos: normas e orientações práticas. (5a ed.), Ed. Universidade de Passo Fundo.

Fernandes, A. D. S. A., et al. (2021). Desafios cotidianos e possibilidades de cuidado com crianças e adolescentes com Transtorno do Espectro Autista (TEA) frente à COVID-19. Cadernos Brasileiros de Terapia Ocupacional, 29.

Giagazoglou, P., Arabatzi, F., Dipla, K., Liga, M. \& Kellis, E. (2012). Effect of a hippotherapy intervention program on static balance and strength in adolescents with intellectual disabilities. Research in Developmental Disabilities, 33(6), 2265-2270.

Gomes, P. T. M., et al. (2015). Autismo no Brasil, desafios familiares e estratégias de superação: revisão sistemática. Jornal de Pediatria, 91(2), 111-121.

Guerrero, M. C. P. \& Alvarez, L. P. (2011). Labor del profesional de enfermería en la equinoterapia como condición esencial para la atención integral al discapacitado. Revista Cubana Enfermeria, Ciudad de la Habana, 27(4), 351-363.

Lima, A. M. M., Silva, H. S. \& Galhardoni, R. (2008). Envelhecimento bem-sucedido: trajetórias de um constructo e novas fronteiras. Revista Interface, 12(27), 795-80.

Maia Filho, A. L. M., et al. (2016). The importance of the family in the care of autist children. Saúde em Foco, 3(1), 66-83.

Maia Filho, A., Almeida, M. T. C., Alves, M. R., Bandeira, L. V. S., Silva, V. B. D., Nunes, N. F. \& Silveira, M. F. (2018). Transtorno do espectro do autismo e idade dos genitores: estudo de caso-controle no Brasil. Cadernos de Saúde Pública, 34, e00109917.

Minayo, M. C. S. (org.) (2016). Pesquisa social: teoria, método e criatividade. Vozes. 
Research, Society and Development, v. 10, n. 11, e145101119495, 2021

(CC BY 4.0) | ISSN 2525-3409 | DOI: http://dx.doi.org/10.33448/rsd-v10i11.19495

Newton, P. (2011). Equoterapia melhora a qualidade de vida de pessoas com deficiência.

Silva, C. L. (2017). Vida adulta e envelhecimento com TEA: tratamento, prognóstico e dificuldades segundo profissionais. 2017. Dissertação (mestrado) Universidade São Judas Tadeu.

Silva C. M., Oliveira V. M., Ferreira C. S., Silva C. S. \& Silva V. L. (2020). Vivência Materna diante do Cuidado à Criança Autista. REVISA. 2020, 9(2): 23140. https://doi.org/10.36239/revisa.v9.n2.p231a240.

Simões, A. L., et al. (2010). Significado da terapia de grupo para crianças autistas: Percepção das mães. Ciência, Cuidado e Saúde, 9(2), 278-284.

Souza, R. F., Skubs, T. \& Brêtas, A. C. P. (2007). Envelhecimento e família: Uma nova perspectiva para o cuidado de enfermagem. Revista Brasileira de Enfermagem, 60(3), 263- 267.

Vergara, S. (2005). Métodos de pesquisa em Administração. Atlas.

Werner, E. \& Dawson, G. (2005). Validation of the phenomenon of autistic regression using home videotapes. Archives of general psychiatry, 62(8), 889-895.

Zanella, L. C. H. (2011). Metodologia de pesquisa. (2a ed.), Departamento de Ciências da Administração/UFSC. 